\title{
ANÁLISE DE RISCO DE SISTEMAS DE PRODUÇÃO DE SUÍNOS, INTEGRADO E INDEPENDENTE, EM PERÍODOS DE ALTA E BAIXA RENTABILIDADE ${ }^{1}$
}

\author{
Denis Teixeira da Rocha \\ Altair Dias de Moura ${ }^{3}$ \\ Ademir Francisco Girotto ${ }^{4}$
}

Resumo - Este trabalho analisou, por meio de um estudo multicasos que abrangia unidades produtoras de suínos, do tipo confinado e de ciclo completo, e os sistemas de produção de suínos, integrado e independente, em períodos de alta e baixa rentabilidade na atividade. O estudo teve como bases o Estado de Santa Catarina (SC), maior produtor nacional de suínos com predomínio da produção integrada, e a região do Vale do Piranga (MG), um dos principais pólos de suinocultura independente do País. Analisou-se a rentabilidade dos dois sistemas por meio da análise do desempenho destes em diferentes cenários, de acordo com situações de mercado comuns ao setor, em períodos específicos. Com base na teoria da firma, foram levantadas estruturas de custos e receitas de seis granjas produtoras de suínos, sendo três pertencentes a cada sistema. Para analisar o desempenho destas, utilizou-se o método de simulação de Monte Carlo. Pelos resultados, verificou-se a possibilidade de obtenção de maior retorno nas granjas do sistema de produção independente, se comparadas às do sistema integrado estudado, durante os períodos de prosperidade da atividade, ao passo que, durante os períodos de crise, essas mesmas granjas apresentaram possibilidade de perdas superiores às das integradas.

Palavras-chave: risco, sistemas de produção, suínos.

Recebido em: 13/12/2006 Aceito em: 31/08/2007

Mestre em Economia Aplicada. E-mail: denistrocha@ hotmail.com

Professor Adjunto do Departamento de Economia Rural da UFV. E-mail: admoura@ufv.br

4 Pesquisador da Embrapa Suínos e Aves. E-mail: afgirotto@cnpsa.embrapa.br 


\section{Introdução}

A suinocultura brasileira é uma atividade importante na geração de trabalho e renda não só no meio rural, mas também nas áreas urbanas. O fato de mais de $70 \%$ da produção suinícola ser destinada ao processamento industrial gera um efeito multiplicador em outros setores da economia, com forte reflexo no meio urbano (Talamini et al., 2006).

O Brasil é o quarto maior produtor e exportador de suínos do mundo. Em 2005, o País bateu novo recorde de exportações, com receita de US\$ 1,16 bilhão, para um volume exportado superior a 625 mil toneladas $23 \%$ da produção nacional (ABIPECS, 2006).

Entretanto, com o surgimento dos casos de febre aftosa no rebanho bovino no Mato Grosso do Sul, em outubro de 2005, vários mercados fecharam suas portas às carnes brasileiras, o que acabou atingindo a carne suína. Nesse contexto, as exportações desse produto tiveram retração em 2006, registrando redução de 15,5\% em volume e de $11,2 \%$ em receita, respectivamente, se comparadas às de 2005 (ABIPECS, 2006).

Com esse embargo, a carne suína, antes destinada ao mercado externo, teve de ser disponibilizada no mercado nacional. No entanto, dado o baixo consumo per capita desse produto no Brasil, o preço recebido por suíno registrou retração devido ao excesso de oferta. Com essa perda de renda do produtor, as indústrias de insumos também ficaram prejudicadas. Nas agroindústrias, por sua vez, as exportações foram reduzidas, o que resultou em queda do faturamento, ou seja, todos os envolvidos na cadeia sofreram as consequiências.

Mais especificamente no setor produtivo, é importante notar a diferença na organização administrativa dos suinocultores, a qual afeta a capacidade destes de competir no mercado. Nesse aspecto, nos sistemas de produção de suínos no Brasil predominam duas formas principais: produção integrada e produção independente. A primeira, típica dos estados da região Sul do Brasil, maior produtora de suínos do País, caracteriza-se 
pela presença de uma empresa abatedora/processadora que integra, verticalmente, várias fases do processo produtivo, como melhoramento genético, nutrição, abate dos animais e processamento da carne, além de fornecer o aparato necessário à criação dos animais pelos suinocultores, geralmente sob a forma de contrato. Nesse arranjo, que cria dependência direta entre produtores e empresa, o suinocultor oferece terra, mão-deobra, instalações e equipamentos e concentra-se na produção dos suínos.

$\mathrm{Na}$ outra forma de organização, denominada independente, não há um vínculo mais intenso entre o suinocultor e as empresas abatedoras/ processadoras. Nesse sistema, os próprios suinocultores compram todos os insumos necessários à produção, desenvolvem o produto e o vendem no mercado. Esse arranjo é mais comum na região Sudeste, com destaque para o estado de Minas Gerais, quarto maior produtor e exportador nacional de carne suína, atrás apenas dos estados da região Sul (ABIPECS, 2006).

Tendo em vista essa diferença na organização administrativa dos sistemas, os produtores de suínos sofrem, em proporção diversa, os efeitos das crises no setor, o que resulta em diferencial de competitividade entre os sistemas. Apesar da escassez de estudos que utilizem metodologias para quantificar as diferenças entre os sistemas integrado e independente, durante esses períodos de alta e baixa na atividade, os agentes desta cadeia pressupõem que o produtor integrado teria uma situação econômica mais estável ao longo dos anos, ou seja, a renda deste não apresentaria grandes alterações durante os ciclos de alta e baixa da atividade. O produtor independente, por sua vez, teria variação maior dos retornos obtidos na atividade, entre os períodos de crise e prosperidade.

Este estudo enfocou o desempenho da suinocultura nacional, durante os últimos anos. Nesse período, a suinocultura brasileira caracterizou-se por ser uma atividade cíclica, cuja duração é determinada pelo trinômio preço do milho e do farelo de soja (i.e., principais componentes da ração e determinantes do custo de produção) e valor recebido pelo suíno, principal componente da receita da atividade (Crivellaro, 2005). Girotto (2006a), ao analisar os resultados obtidos pela suinocultura catarinense a 
partir de 1995, destacou a existência de um breve período de resultados positivos e outro, mais longo, de resultados negativos, que se repetiam periodicamente com intensidade e durabilidade variada. Segundo Girotto (2006b), de 1998 a 2003, a suinocultura apresentou ciclos de resultados positivos, em média, a cada dois anos.

Dada a escassez de trabalhos que mostrem, por meio de metodologia quantitativa, se há diferenças entre os sistemas suinícolas, integrado e independente, nas diferentes fases da atividade, este trabalho objetivou analisar o desempenho econômico, sob condições de risco, de granjas de produção suinícola, componentes desses dois sistemas, em períodos de "alta" (prosperidade) e "baixa" (crise) na atividade. Assim, buscou-se avaliar a amplitude de variação dos resultados econômicos, nesses dois períodos, e o comportamento de cada sistema produtivo perante tais situações de mercado, tendo como bases o pólo de suinocultura do Vale do Piranga (MG) - sistema independente de produção, e o estado de Santa Catarina (SC) - sistema integrado.

\subsection{Histórico recente da suinocultura brasileira}

A suinocultura brasileira é uma atividade cíclica, visto que alterna períodos de alta e baixa rentabilidade, definidos pelo trinômio preço do milho, do farelo de soja e do suíno. Assim, conforme a combinação de preços desses produtos, o suinocultor pode alcançar retornos positivos na atividade (períodos de alta) ou enfrentar prejuízos, dado o maior custo de produção diante do preço recebido pelo suíno terminado (períodos de baixa).

De 2002 a 2003, a suinocultura brasileira enfrentou o que foi, para muitos, considerada a pior crise da história da atividade. Essa crise teve origem em 2001, em virtude dos bons resultados da atividade, associados às crescentes exportações da carne suína brasileira, que impulsionaram o crescimento do rebanho nacional, o que levou a significativo crescimento da oferta de suínos no mercado. No entanto, esse fato coincidiu com o aumento no custo de produção, devido principalmente às altas do milho e 
da soja, e com a queda da demanda, impulsionada pela redução na renda da população. Em resumo, houve aumento da oferta associado à redução na demanda e ao aumento no custo de produção (Moura et al., 2005). Com isso, os produtores tiveram que amargar um longo período de crise, cujo resultado foi a redução do plantel com significativa diminuição no número de produtores e descapitalização dos que ainda se mantinham na atividade (PORKWORLD, 2003).

Por sua vez, do final de 2004 a meados de 2005, a suinocultura nacional atravessou um período com características inversas. Com o preço dos insumos em baixa, o custo de produção foi reduzido, ao mesmo tempo que o preço do suíno se valorizou. Dessa forma, o produtor teve maior possibilidade de cobrir todos os seus custos, além de garantir uma sobra de caixa que permitisse sua capitalização ou, pelo menos, recuperação de parte do prejuízo causado pelas crises anteriores. Essa conjugação de preços se deu pelo aumento das exportações no ano de 2004 e, principalmente, em 2005, conjugado com a elevação do preço da carne suína no mercado internacional. Além disso, a oferta brasileira de suínos encontrava-se em equilíbrio, em virtude da redução do plantel ocorrida na crise 2002/2003 e do aumento das exportações, o que contribuiu para melhorar o preço pago ao produtor (ABIPECS, 2006).

Na Figura 1 é possível visualizar as conjugações dos preços dos insumos e do produto, os quais determinaram a crise da suinocultura em 2002/ 2003 (período 1 - baixa) e, posteriormente, o período de prosperidade subseqüente (período 2 - alta), nos anos de 2004 e 2005. 


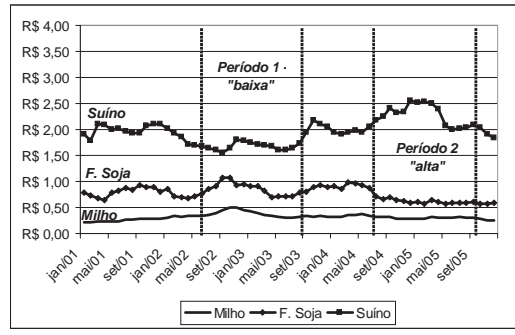

(a) Região do Vale do Piranga (MG)

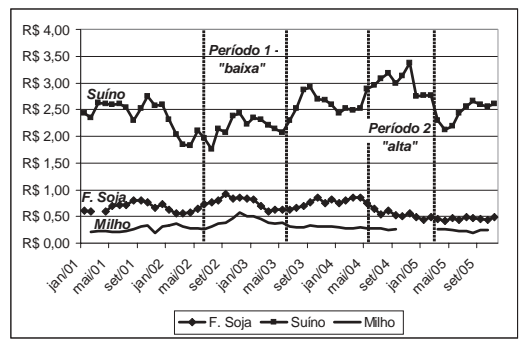

(b) Estado de Santa Catarina (SC)

Figura 1 - Comportamento dos preços pagos pelo milho e farelo de soja e do preço recebido pelo suíno, no Vale do Piranga (MG) e no estado de Santa Catarina - 2001 a 2005.

Nesse contexto, os períodos de baixa e alta na atividade foram assim definidos:

- Sistema de produção independente do Vale do Piranga (MG):

- Baixa: julho/2002 a junho/2003; Alta: junho/2004 a março/ 2005.

- Sistema de produção integrado do Estado de Santa Catarina (SC):

- Baixa: junho/2002 a setembro/2003; Alta: julho/2004 a outubro/2005.

Fonte: Embrapa, Asemg.

\section{Metodologia}

A teoria da firma, que tem como unidade principal de análise a empresa individual, busca analisar como a empresa tenta maximizar seus lucros tendo por restrições o custo dos fatores de produção, o preço do produto e a fronteira tecnológica de produção (Santos; Lírio, 2004). O lucro em uma atividade produtiva é dado pela diferença entre a receita total (RT) e o custo total (CT). Assim, para determinar o lucro é necessário conhecer a receita e os custos da empresa, razão pela qual o conhecimento dos custos de produção de uma atividade é essencial para o efetivo controle da empresa e para o processo de tomada de decisão.

Na atividade suinícola, os estudos sobre custos de produção são de grande importância, visto que refletem o nível tecnológico e a eficiência com que a atividade é desenvolvida e podem definir o sucesso do negócio (Girotto; Santos Filho, 2000). 
Segundo Binger e Hoffman (1998), há duas maneiras equivalentes de definir custos econômicos. Na primeira, os custos são caracterizados pelo valor de mercado de todos os insumos usados na produção; na segunda, conceituam-se custos econômicos como o valor de mercado da melhor alternativa de emprego dos recursos utilizados no processo produtivo.

Outra definição importante refere-se aos custos fixos e variáveis. Segundo a teoria econômica, no curto prazo, alguns dos insumos de produção de uma empresa são fixos, enquanto outros podem ter variação, o que possibilita modificações na taxa de produção da empresa. Nesse contexto, o custo total da produção tem dois componentes, quais sejam, o custo fixo $(\mathrm{CF})$, que existirá independentemente do nível de produção da empresa, e o custo variável (CV), que varia conforme o nível de produção (Pindyck; Runbinfeld, 1994).

Neste trabalho adotaram-se as definições de custos de produção, propostas pelo Instituto de Economia Agrícola de São Paulo (Matsunaga, 1976). Assim, têm-se:

Receita Total (RT): composta por todas as entradas monetárias provenientes da venda dos animais terminados.

Custo Operacional Efetivo (COE): desembolsos diretos para a compra de insumos (insumos alimentares, medicamentos, energia, mão-de-obra, transporte, etc.).

Custo Operacional Total (COT): COE acrescido da depreciação de máquinas e equipamentos e a remuneração da mão-de-obra familiar, se existir.

Custo Total (CT): COT acrescido da remuneração do capital médio empatado (custo de oportunidade do capital). 
Com base nos itens de custos, o trabalho utilizou três medidas de resultado econômico, com vistas em avaliar economicamente os sistemas estudados, conforme segue.

- Margem Bruta Total (MBT): diferença entre a RT e o COE. Indica se os custos diretos da empresa estão sendo compensados e reflete sua sustentabilidade no curto prazo.

- Margem Líquida (ML): diferença entre a RT e o COT. Mostra se a empresa está se capitalizando, ou não, e indica sua sustentabilidade no longo prazo.

- Lucro (L): diferença entre a RT e o CT. Este indicador demonstra se o retorno da atividade é maior, ou não, que a rentabilidade da atividade alternativa para o capital investido.

A atividade suinícola, assim como qualquer outra, está sujeita a riscos. Assim, é comum associar o risco envolvido na atividade com seu retorno esperado. $\mathrm{O}$ risco reflete a incerteza quanto ao alcance dos resultados planejados previamente (Woiler; Mathias, 1996). Do ponto de vista técnico, há pelo menos duas opções para análise do risco, quais sejam, análise de sensibilidade e análise de probabilidade (Noronha, 1991).

A análise de sensibilidade verifica o efeito de variações nos parâmetros e variáveis determinantes dos custos e receitas da atividade sobre seus indicadores econômicos. Esta análise determina quais são os parâmetros e, ou, variáveis mais importantes na determinação do resultado econômico da atividade. Já a análise de probabilidade tem como técnica mais usada o método de simulação, que constitui na representação dinâmica de um sistema mediante um modelo. A simulação de dados permite o cálculo de diferentes combinações que probabilisticamente podem ocorrer, cujo resultado é a distribuição de freqüências, traduzindo em números o aspecto risco (Noronha, 1991).

Nesse contexto, a simulação de Monte Carlo, utilizada neste trabalho, tem sido uma ferramenta útil a tomadores de decisão, quando consideram 
situações sujeitas a risco em seus projetos. Essa simulação é um método prático pelo qual se utiliza distribuição de probabilidade na análise do risco, possibilitando uma leitura simplificada da interpretação do risco associado aos sistemas de produção.

Assim, o método de Monte Carlo foi operacionalizado da seguinte forma para análise das granjas representativas dos dois sistemas de produção de suínos estudados:

1) Caracterização dos dois sistemas de produção por meio da modelagem de estruturas de custos e receitas da atividade. Essa estrutura, baseada em Girotto e Santos Filho (2000), englobou um ciclo de produção que abrangeu todos os itens de custos e receitas, do nascimento do leitão até o animal terminado, entregue para abate.

2) Seleção das variáveis de entrada (de risco): preço do suíno terminado, preço do milho e do farelo de soja e número de leitões terminados/porca/ ano. As três primeiras variáveis tiveram distribuição de probabilidade identificada por histograma, com base na série histórica dos dados coletados, enquanto a última apresentou distribuição triangular, sendo a produtividade atual (média anual coletada) o valor mais provável e considerando uma variação de 1,5 suíno terminados por matriz/ano, para cima e para baixo, para definição dos limites superior e inferior de variação, respectivamente.

3) Seleção das variáveis de análise (de saída): indicadores de resultado econômico das empresas, expressos em matriz/ano (Margem Bruta, Margem Líquida e Lucro).

4) Por fim, geraram-se as simulações, realizadas no software “@ Risk 4.5", para os dois períodos em estudo, separadamente, pela execução do modelo 5.000 vezes, considerando um nível de convergência dos resultados das variáveis de análise inferior a 1,5\%.

Neste trabalho utilizou-se a metodologia de estudos de casos, na sua variável de casos múltiplos. Esse levantamento multicasos constou de 
seis granjas de produção de suínos, confinado de ciclo completo, três em cada região, divididas conforme o número de matrizes alojadas. Com base na escala de produção, foram obtidos três grupos: Grupo 1: 105 125 matrizes; Grupo 2: 170 - 190 matrizes; e Grupo 3: 400 - 420 matrizes.

A escolha dos grupos baseou-se na divisão dos produtores conforme o número de matrizes alojadas nas duas regiões, com vistas em obter um padrão de comparação ${ }^{5}$.

Nas simulações foram considerados dois cenários distintos, diferenciados pelo preço recebido pelo suíno, nas granjas do sistema de produção integrado. No cenário 1 considerava-se que o suíno era remunerado, no sistema integrado, com base no preço de referência estabelecido pelo Sindicarnes - SC, sem bonificação ou penalização. Já no cenário 2, o preço do suíno nesse sistema era o de referência, acrescido da bonificação máxima dada pela integradora (acréscimo de $8 \%$ ). Nos dois cenários, o preço recebido pelo suíno, no sistema independente, era determinado pela Bolsa do Suíno de Belo Horizonte.

\subsection{Fonte de dados}

As séries de dados das variáveis de entrada - preço do milho, do farelo de soja e do suíno terminado - tiveram duração de cinco anos, de 2001 a 2005. Os dados dessas séries, referentes aos produtores integrados do Estado de Santa Catarina, foram obtidos do Centro Nacional de Pesquisa de Suínos e Aves - CNPSA/Embrapa, enquanto os dados representativos do sistema independente, válidos para a região do Vale do Piranga (MG), foram obtidos de registros de um produtor de suínos da região, no caso dos preços do milho e do farelo de soja, e junto à ASEMG, no caso de dados de preço do suíno.

\footnotetext{
A fixação do grupo de maior escala na faixa de 400 matrizes deveu-se à dificuldade de encontrar produtores de ciclo completo de escala superior a essa, no sistema integrado de Santa Catarina.
} 
A taxa de juros utilizada no cálculo do custo de oportunidade foi da caderneta de poupança (rendimento mensal $=0,6632 \%$ ), obtida do IPEA (base de maio de 2006). Ademais, todas as séries de preços foram deflacionadas por meio do IGP - DI, fornecido pelo IPEA, com base no mês de maio de 2006.

\subsection{Caracterização dos sistemas de produção}

2.2.1. Sistema de produção de suínos independente do Vale do Piranga (MG)

A região do Vale do Piranga está situada ao norte da Zona da Mata mineira e abriga um dos principais núcleos especializados em suinocultura independente do país, o qual se destaca pela tecnificação das granjas e por sua localização geográfica estratégica.

A granja suinícola 1, representativa do sistema independente e situada em Ponte Nova (MG), possuía 125 matrizes alojadas e produtividade média de 22,5 terminados por matriz/ano. Os animais vendidos para abate tinham peso médio de $98 \mathrm{~kg}$, aos 145 dias de idade, para uma conversão alimentar de 2,47:1. Por sua vez, a granja de produção suinícola 3, localizada em Santa Cruz do Escalvado (MG), possuía 189 matrizes e produtividade média de 22,5 terminados por matriz/ano. Os animais para abate tinham peso médio de $92,45 \mathrm{~kg}$, aos 146 dias, para uma conversão alimentar de 2,48:1. A granja suinícola 5, situada em Urucânia (MG), possuía 420 matrizes e produtividade média de 25,5 terminados por matriz/ ano. Os animais para abate tinham peso médio de $104,25 \mathrm{~kg}$, aos 165 dias, com conversão de 2,65:1.

2.2.2. Sistema de produção de suínos integrado do estado de Santa Catarina

O estado de Santa Catarina é considerado o maior produtor e segundo exportador nacional de carne suína, visto que concentra, 
aproximadamente, $24,31 \%$ do total de carne suína produzida e $34,3 \%$ das exportações de carne suína do país (ABIPECS, 2006).

A granja suinícola 2, componente do sistema integrado e localizada na região de Concórdia, possuía 108 matrizes alojadas e produtividade de 22,5 terminados por matriz/ano. Os animais eram terminados com 102 kg em média, aos 150 dias, com conversão alimentar de 2,49:1. A granja 4, também situada em Concórdia, possuía 172 matrizes e produtividade média de 21,5 terminados por matriz/ano. Nesta granja, os animais eram terminados com $94 \mathrm{~kg}$ aos 145 dias, em média, com conversão de 2,54:1. Por fim, a granja suinícola 6, localizada em Braço do Norte, detinha 400 matrizes e produtividade de 23 terminados por matriz/ano. Os animais eram terminados com 104 kg em média, aos 162 dias, com conversão de $2,68: 1$

\section{Resultados e discussão}

Os resultados da pesquisa revelaram que, durante o período de baixa (crise), todas as granjas suinícolas componentes dos dois sistemas de produção em estudo tiveram resultados de desempenho econômico predominantemente negativos, com probabilidades ínfimas de obter resultados positivos para os indicadores Margem Bruta (MB), Margem Líquida (ML) e Lucro (L). As granjas suinícolas independentes (granjas 1,3 e 5) tiveram probabilidades de $2,75 \%, 0,35 \%$ e $0,30 \%$ para MB, ML e L maiores que zero, respectivamente. Por sua vez, as granjas de produção de suínos integradas (granjas 2, 4 e 6) apresentaram resultados ainda piores, com probabilidade de obtenção de MB, ML e L positivas iguais a zero, no cenário 1 , e de $2 \%, 0,35 \%$ e $0,25 \%$, no cenário 2 .

Dessa forma, durante o período de crise, 2002/2003, as granjas suinícolas representativas dos sistemas de produção de suínos, integrado e independente, operaram, quase que totalmente, no prejuízo e não conseguiram cobrir os gastos diretos com a atividade (MB negativa) e muito menos a depreciação das instalações e equipamentos (ML negativa), 
o que resultou em descapitalização dos produtores, com comprometimento da sustentabilidade do negócio no longo e até no curto prazo. Esses resultados justificam os casos de abandono da atividade por parte de muitos produtores e a descapitalização dos que permaneceram na atividade após essa crise, fatos citados constantemente em revistas especializadas.

Essa situação é reforçada ao analisar os valores médios das medidas de resultado econômico nesse período. Ao considerar o prejuízo total médio/ ano $^{6}$, as granjas de produção suinícola independente 1, 3 e 5 apresentaram

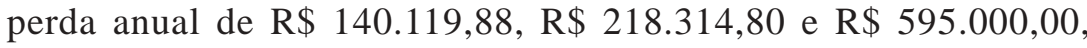
respectivamente. Já no sistema integrado, essa perda média foi de $\mathrm{R} \$$ 166.026,16, R \$ 257.972,40 e R \$ 641.346,60, no cenário 1, e de $\mathrm{R} \$$ $132.577,56, \mathrm{R} \$ 210.846,00$ e $\mathrm{R} \$ 519.593,00$, no cenário 2, para as granjas suinícolas integradas 2, 4 e 6, respectivamente. Esses resultados demonstram a grande perda de capital dos produtores durante esses períodos de baixa e, portanto, a necessidade de uma reserva de caixa para suportar esses períodos críticos, principalmente pelos produtores independentes, que dependem de capital de giro próprio.

Por sua vez, ao analisar os valores mínimos obtidos pelas granjas nesse período, expressos em matriz/ano, constata-se que as granjas integradas (granjas 2, 4 e 6) apresentaram valores maiores que os obtidos pelas granjas do sistema independente (granjas 1, 3 e 5), $\mathrm{R} \$ 448,33$, no cenário 1, e $\mathrm{R} \$ 644,77$, no cenário 2, considerando a média da diferença entre os valores obtidos pelas granjas de mesma escala nos dois sistemas, em todos os indicadores de desempenho econômico (MB, ML e L). Esse fato comprova a possibilidade de perdas mais elevadas no sistema de produção independente, quando comparado com o integrado.

É interessante notar que, na análise de sensibilidade das variáveis de entrada do estudo, o preço pago por quilograma do milho teve maior influência nos indicadores de desempenho econômico, seguido pela

Valor gerado pela multiplicação do valor médio do lucro/matriz/ano, obtido nas simulações, pelo número médio de matrizes alojadas por grupo de escala de produção (grupo 1: 116; grupo 2: 180; grupo 3: 410 matrizes). 
variável preço recebido por quilograma de suíno terminado. Essa constatação confirma o fato de terem sido os preços do milho e do suíno os grandes causadores da crise da suinocultura brasileira em 2002/2003.

No outro extremo, quando se analisam os resultados econômicos obtidos pelas granjas de produção suinícola em um período de alta (ou prosperidade) na atividade, os resultados invertem. Nessa situação, todas as granjas apresentaram 100\% de probabilidade de obtenção de medidas de resultado econômico positivo, com exceção das granjas suinícolas integradas com remuneração do suíno igual ao preço de referência sem bonificação (cenário 1), as quais apresentaram pequena chance (menor que $10 \%$ ) de obter margem líquida e lucro negativos.

Nessa situação, as granjas suinícolas independentes superaram as integradas, em relação aos valores dos indicadores de desempenho econômico (MB, ML e L). A diferença média entre esses indicadores ${ }^{7}$ foi de $\mathrm{R} \$ 1.156,05$, por matriz/ano, no cenário 1 (Anexo 1), e de $\mathrm{R} \$$ 772,31, no cenário 2 (Anexo 2), sempre em favor das granjas do sistema independente.

No que se refere aos valores máximos obtidos nas simulações, as granjas independentes apresentaram resultado ainda melhor, com diferença média entre os indicadores MB, ML e L das granjas do sistema independente, em relação às integradas, de $\mathrm{R} \$ 1.482,30$, por matriz/ano, no cenário 1 , e de $\mathrm{R} \$ 1.085,51$, por matriz/ano, no cenário 2. Esses resultados demonstram a possibilidade de obtenção de retornos mais elevados, durante os períodos de alta na atividade, nas granjas do sistema de produção independente, em relação aos resultados alcançados pelo sistema integrado do estudo.

Quando se considera o número médio de matrizes alojadas por grupo de produtores (grupo 1: 116; 2: 180; 3: 410 matrizes), verifica-se que as granjas do sistema independente (1, 3 e 5) tiveram lucro médio anual de

Média da diferença entre os valores médios dos indicadores (MB, ML ou L) por matriz/ano, obtidos nas simulações, das granjas suinícolas independentes e integradas. 
$\mathrm{R} \$ 193.228,16, \mathrm{R} \$ 269.456,40$ e $\mathrm{R} \$ 798.548,80$, respectivamente, com mais de $50 \%$ de probabilidade de obter resultados superiores a esses.

As granjas integradas, por sua vez, também tiveram retornos elevados, mas inferiores aos resultados das granjas do sistema independente. Levandose em conta o número médio de matrizes alojadas por propriedade, as granjas integradas 2, 4 e 6 tiveram lucro médio anual, no cenário 1, de R \$ $71.768,04, \mathrm{R} \$ 71.553,60$ e $\mathrm{R} \$ 258.816,60$, e de $\mathrm{R} \$ 119.031,08, \mathrm{R} \$ 136.629,00$ e $\mathrm{R} \$ 415.498,10$, no cenário 2, respectivamente, com pouco mais de $50 \%$ de probabilidade de obter valores superiores a esses. 
REVISTA DE ECONOMIA E AGRONEGÓCIO, VOL.5, $N^{\circ} 3$

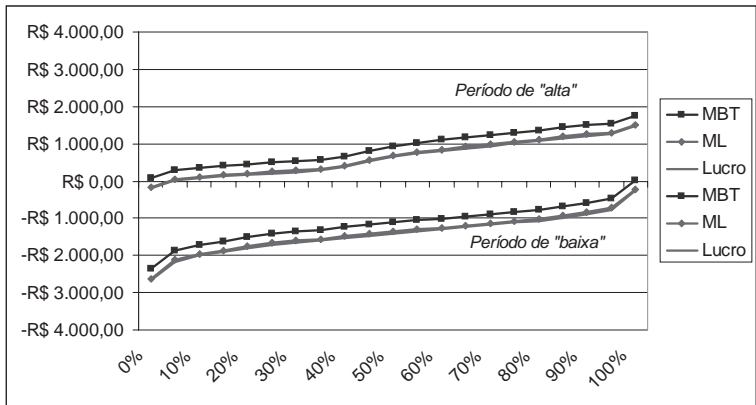

(a) Sistema de produção independente.

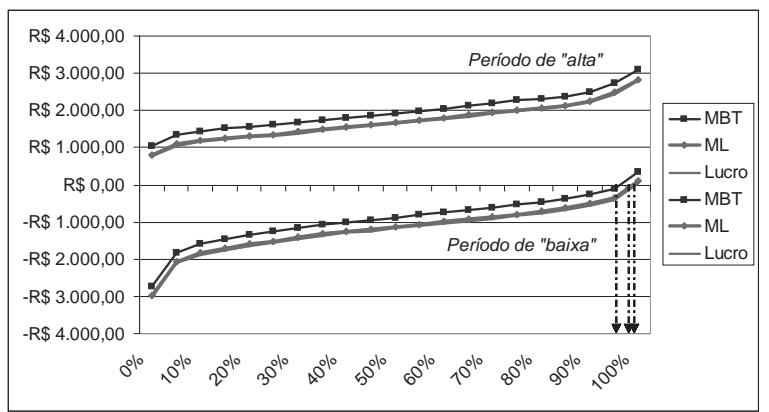

(b) Sistema de produção integrado - cenário 1 .

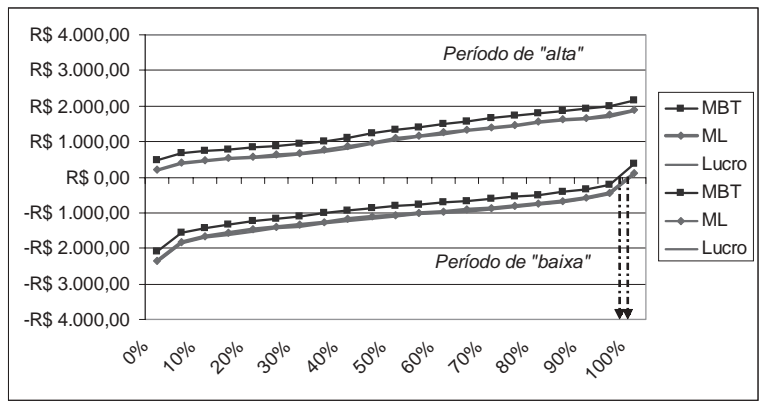

(c) Sistema de produção integrado - cenário 2.

Figura 2 - Curvas de probabilidade acumulada da MBT, ML e Lucro, por matriz/ano, para os sistemas independente e integrado, em períodos de alta e baixa na atividade.

Fonte: Dados da pesquisa. 
A Figura 2 ilustra o comportamento das curvas de probabilidade acumulada para os indicadores MB, ML e Lucro, por matriz/ano, das granjas dos sistemas independente (Figura 2a) e integrado, nos cenários 1 (Figura 2b) e 2 (Figura 2c). Essas figuras demonstram a menor variação dos resultados econômicos entre os períodos de alta e baixa, no sistema integrado (menor distância entre as curvas dos dois períodos), e os valores mais elevados obtidos pelo sistema independente, nos períodos de alta (curvas em um patamar mais elevado no gráfico).

Os resultados destacaram o maior retorno obtido pelas granjas componentes do sistema de produção independente, durante os períodos de alta na atividade, ao passo que, durante os períodos de crise, essas mesmas granjas apresentaram possibilidade de perdas superiores às do sistema integrado. Dessa forma, os resultados indicaram que o sistema de produção integrado foi o mais estável, entre esses períodos de alta e baixa.

Entretanto, ao contrário das granjas independentes estudadas, as integradas não conseguiram, na média, cobrir as perdas do período de crise com os ganhos do período de alta subseqüente ${ }^{8}$. Já no sistema independente, apesar das perdas elevadas durante a crise, as granjas tiveram grande probabilidade de recuperar essas perdas, no período de alta.

Ao analisar os fatores-chave de tais resultados, tem-se que as granjas do sistema integrado apresentaram menor custo de produção nos três grupos estudados, sendo que o custo de logística, associado ao transporte de insumos à granja, foi o principal determinante dessa diferença em relação às granjas do sistema independente. Esse menor custo está relacionado com o fato de a região do Vale do Piranga (MG) ser distante dos principais centros de produção de grãos do País, razão pela qual tem de arcar com fretes elevados, ao passo que, no sistema integrado estudado, tais insumos são fornecidos pela própria empresa integradora,

Comparação entre os valores médios das perdas (prejuízos) ocorridas no período de baixa com os retornos médios alcançados no período de alta analisado. 
representando um pequeno valor referente ao transporte destes até a granja. Assim, esse menor custo de produção propiciou às granjas integradas menores perdas durante o período de crise. Por outro lado, ao avaliar o melhor desempenho econômico das granjas do sistema independente durante o período de alta, tem-se o preço recebido pelo suíno terminado como principal determinante, apesar do maior custo de produção dessas granjas diante do sistema integrado. Esse maior valor pago ao produtor pelo suíno foi possível devido à forma de atuação dos produtores no mercado, que tinham liberdade para escolherem seus compradores e, assim, obterem melhores preços pelo suíno terminado, fruto da estrutura independente.

É interessante notar que, comparativamente, os custos de produção e a estrutura produtiva das granjas estudadas não foram muito divergentes em termos de eficiência técnica. Assim, a comparação entre as granjas dos dois sistemas de produção permitiu apontar questões regionais como um fator importante ligado à eficiência econômica das unidades produtivas. Como os principais pólos de produção de suínos, normalmente, apresentam elevada eficiência zootécnica, pode-se dizer que condições relacionadas com os arranjos produtivos locais e suas estruturas de mercado podem ser determinantes na competitividade de regiões produtoras de suínos. Neste caso, a localização geográfica próxima às áreas fornecedoras de insumos de produção, assim como aos centros de abate e processamento da carne, pode trazer vantagens importantes para a competitividade dos suinocultores de tal região. Esse fato pode explicar a tendência de ampliação da produção de suínos na região Centro-Oeste do Brasil, grande produtora nacional de grãos, e a expansão de unidades de abate e processamento da carne nessa região.

Por fim, com base nos resultados do trabalho e nas informações levantadas sobre esses sistemas, conclui-se que o sistema de produção de suínos independente do Vale do Piranga (MG) tenha um foco mais empresarial. Esse sistema se mostrou mais vulnerável às oscilações de mercado que afetaram a atividade, porém apresentou grandes chances de aproveitar os períodos favoráveis ao setor. Dessa forma, constata-se 
que o sistema de produção suinícola independente é um negócio arriscado e dependente de um planejamento de longo prazo, com vistas em buscar um balanço de seu desempenho econômico entre os períodos de alta e baixa na atividade.

Em contrapartida, o sistema de produção de suínos integrado de Santa Catarina caracteriza-se mais como uma atividade de subsistência. Essa pressuposição baseia-se na maior estabilidade do negócio ao longo dos anos, associada aos retornos menores, quando em comparação com as granjas do sistema independente do estudo. A dependência dos suinocultores da empresa integradora determina essa situação. A empresa integradora atua, de certa forma, como uma guardiã dos suinocultores, em termos de risco, já que reduz as suas possibilidades de perdas e possibilita a eles produzir com menores custos operacionais. Conseqüentemente, os suinocultores integrados abrem mão, intencionalmente ou não, da possibilidade de altos lucros em detrimento do menor risco do negócio.

\section{Conclusão}

A suinocultura brasileira é uma atividade cíclica, visto que a duração do ciclo é determinada pelo trinômio preço do milho e do farelo de soja e valor pago pelo suíno. Nesse cenário, os produtores de suínos, conforme a organização administrativa na qual estão inseridos, seja produção independente ou integrada, sofrem, em proporção diversa, os efeitos dessas mudanças de mercado que afetam a atividade.

Os resultados do trabalho, focado em um estudo multicasos que envolveu produtores de suínos independentes do Vale do Piranga (MG) e integrados do Estado de Santa Catarina, indicaram a possibilidade de perdas mais elevadas, durante os períodos de crise, nas granjas do sistema de produção independente diante das granjas do sistema integrado analisado. Entretanto, quando a atividade se encontrava em alta, os produtores independentes apresentaram desempenho econômico superior dos 
integrados, com ganhos médios superiores às perdas ocorridas no período de baixa analisado, resultado não alcançado pelas granjas suinícolas do sistema integrado.

Dessa forma, o trabalho dá suporte às percepções informais dos agentes envolvidos no setor de suinocultura de que as granjas do sistema integrado têm uma situação mais estável entre os períodos de alta e baixa na atividade, mas com possibilidades reduzidas de altos retornos. Enquanto isso, os produtores independentes têm a possibilidade de enfrentar grandes perdas econômicas nos períodos de baixa, mas que podem ser compensadas pelos ganhos possíveis durante os períodos de alta na atividade.

Tal comportamento tem como base a própria estrutura da cadeia produtiva em que se estabelece cada sistema suinícola. Na suinocultura independente, a relação é típica de mercado aberto, no qual os produtores estão mais expostos aos prejuízos oriundos da crise, mas também podem colher, em maior escala, os ganhos dos períodos de prosperidade. Portanto, esses produtores estão mais expostos aos riscos da atividade, por sua vez, a estrutura do sistema integrado apresenta forte ligação entre empresas integradoras e suinocultores. Nesse caso, o suinocultor está exposto a menor risco, que é transferido, em parte, para a empresa integradora, e a consequiência dessa menor exposição ao risco se traduz na redução das possibilidades de alcance de altos retornos com a atividade.

Por fim, é interessante notar que alguns fatores determinantes dos resultados apresentados podem estar mais ligados às questões regionais relacionadas com arranjos produtivos locais e suas estruturas de mercado, do que com a eficiência técnica das unidades produtivas, sendo que essas diferenças podem não se expressar em tal magnitude, ao estudar esses dois sistemas em diferentes regiões. Essas diferenças relacionam-se, principalmente, com o menor custo de produção no sistema integrado, que, no presente trabalho, foi determinado principalmente pela logística de aquisição de insumos e até mesmo pelo preço do suíno terminado no sistema independente, principal determinante de seu melhor desempenho econômico durante o período de alta. 


\section{Referências}

ABIPECS - Associação Brasileira das Indústrias Produtoras e Exportadoras de Carne Suína. Carne Suína Brasileira em 2006. Disponível em: www.abipecs.org.br . Acesso: 9 jun. 2006.

ASEMG - Associação dos Suinocultores do Estado de Minas Gerais. Cotações do Suíno. Disponível em: www.asemg.com.br. Acesso: 28 set. 2006.

BINGER, B. R., HOFFMAN, E. Microeconomics with calculus. $2^{\circ}$ edição. EUA: Addison-Weslwy, 1998. 633 p.

CRIVELLARO, A. Os ciclos econômicos da suinocultura: entender para sobreviver e prosperar na atividade. In: Suinocultura Industrial, $n^{\circ}$. 02, ed. 185. Porto Feliz, SP. p.28-30.

CENTRO NACIONAL DE PESQUISA DE SUÍNOS E AVES EMBRAPA. Levantamento de preços de milho, farelo de soja e suínos no Estado de Santa Catarina. Concórdia: Embrapa Suínos e Aves, 2006. Comunicado Pessoal.

GIROTTO, A. F. (a) Análise do Mercado Suinícola. Disponível em: http:/ /www.cnpsa.embrapa.br/artigos. Acesso: 20 nov. 2006.

GIROTTO, A. F. (b) Análise da Suinocultura Catarinense. Disponível em: http://www.cnpsa.embrapa.br/artigos. Acesso: 20 nov. 2006.

GIROTTO, A. F., SANTOS FILHO, J. I. Custos de produção de suínos. Concórdia: Embrapa Suínos e Aves, 2000. 36p. (Documentos, $62)$.

IPEA - Instituto de Pesquisa Econômica Aplicada. IPEADATA. Disponível em: www.ipeadata.gov.br. Acesso: 28 set. 2006. 
MATSUNAGA, M. et al. Metodologia de custo de produção utilizada pelo IEA. São Paulo: Agricultura em São Paulo, Ano XXIII, 1976.

MOURA, A. D.; LÍRIO, V. S.; SILVA JÚNIOR, A. G. Diagnóstico da Cadeia Produtiva da Suinocultura da Região de Pará de Minas MG. SEBRAE - MG, 2005. 96p.

NOROnhA, J. F. Projetos Agropecuários: Administração financeira, orçamentação e avaliação econômica. São Paulo: FEALQ, 1991.

PINDYCK, R., RUBINFELD, D. Microeconomia. São Paulo: Makron Books, 1994.968p.

PorkWorld. Editora Animal World. Paulínia - S.P, V.3 n. 17, dezembro 2003.

SANTOS, M. L., LÍRIO, V. S. Teoria Microeconômica. Viçosa: UFV, 2004. Apostila da disciplina ERU 500 - Introdução ao Estudo de Economia.

TAlamini, D. J. D., MARTins, F. M., PINHEIRO, A.C. A. Rentabilidade da terminação de suínos no Estado de Santa Catarina. Embrapa: Concórdia, 2005. Comunicado Técnico 404. Disponível em: www.cnpsa.embrapa.br. Acesso: 14 mar. 2006.

WOILER, S., MATHIAS, W. F. Projetos: planejamento, elaboração e análise. São Paulo: Atlas, 1996. 
Abstract - This research analyzed the integrated and independent systems of pork production in Brazil, using multiple case studies, which focused on confined and complete-cycle producing units of swines, in the high and low profits periods of the activity. The study focused on the pork production of the State of Santa Catarina (SC), Brazilian's greatest producer of swines, and presenting the predominance of integrated production, and on the Vale do Piranga (MG) region, one of the main Brazilian regions of the independent production system. The work analyzed the yield of the two systems of pork production through the analysis of the performance of each system in different scenarios. The costs and incomes (economic efficiency) of six producing pork farms, in which three belonged to one production system and three to the other, was the basic analytical structure of the study. The Monte Carlo method was used to analyze the performance of each farm. Considering the comparison between the two production systems in different time periods, in prosperity time, the independent pork production farms presented higher returns. On the other hand, in period of crisis, the integrated production system farms were more successful in terms of performance, as the independent ones presented higher losses.

Key words: Risk, production system, pork production. 
REVISTA DE ECONOMIA E AGRONEGÓCIO, VOL.5, $N^{o} 3$ 